\title{
Molecular tectonics: a node-and-linker building block approach to a family of hydrogen bonded frameworks
}

\author{
Stephanie A. Boer, ${ }^{[a]}$ Mahbod Morshedi, ${ }^{[a]}$ Andrew Tarzia, ${ }^{[b, c]}$ Christian J. Doonan, ${ }^{\left[{ }^{[c]}\right.}$ and Nicholas G. \\ White ${ }^{\star[a]}$
}

\begin{abstract}
While numerous hydrogen bonded organic frameworks (HOFs) have been reported, typically these cannot be prepared predictably or in a modular fashion. In this work, we report a family of nine diamondoid crystalline porous frameworks assembled via hydrogen bonding between poly-amidinium and poly-carboxylate tectons. The frameworks are prepared at room temperature in either water or water/alcohol mixtures. Importantly, both the cationic and anionic components can be varied and additional functionality can be incorporated into the frameworks, which show good stability including to prolonged heating in DMSO or water.
\end{abstract}

\section{Introduction}

Building upon Ermer ${ }^{[1]}$ and Wuest's ${ }^{[2]}$ pioneering studies in the late 1980s and early 1990s, the field of three-dimensional networks assembled by hydrogen bonding has expanded rapidly in the last decade, stimulated in part by the demonstration that these materials can be surprisingly stable and/or permanently porous. ${ }^{[3]}$ Frequently described as HOFs (hydrogen bonded organic frameworks), the last few years have seen applications of these materials in a range of applications including gas storage and separation, ${ }^{[4]}$ proton conduction ${ }^{[5]}$ and molecular sensing. ${ }^{[6]}$

While a range of impressive properties have been realized, synthetic routes towards hydrogen-bonded materials are neither as predictable nor as general as is the case for related network solids such as metal organic frameworks ${ }^{[7]}$ (MOFs) or covalent organic frameworks ${ }^{[8]}$ (COFs). HOFs are typically synthesized from self-complementary recognition motifs such as carboxylic acids, pyridone and diaminotriazines (Figure 1), however this strategy has not realized large families of structurally related materials. ${ }^{[3]}$

An alternative approach to constructing HOFs is to employ charged building units. This has the advantage that the hydrogen bonds holding the material together are strengthened by electrostatic attraction. In addition, employing two discrete building units allows for the application of a node-and-linker concept, which has underpinned the field of reticular chemistry, ${ }^{[7 \mathrm{~b}}$ 9] to be translated to HOFs. Indeed, several interesting materials have been prepared from pairs of charged components, including

[a] Dr S. A. Boer, Dr M. Morshedi, Dr N. G. White

Research School of Chemistry, The Australian National University Canberra, ACT, Australia

E-mail: nicholas.white@anu.edu.au

URL: www.nwhitegroup.com

[b] Mr A. Tarzia

Department of Chemistry, Molecular Sciences Research Hub, White City Campus, Imperial College London, United Kingdom

[c] Mr A. Tarzia, Prof. C. J. Doonan

Department of Chemistry and Centre for Advanced Materials, The University of Adelaide, SA, Australia

Supporting information for this article is given via a link at the end of the protonated amines with anions, ${ }^{[5 c, 10]}$ and guanidinium cations with anions. ${ }^{[3 c, 11]}$ Notably, Ward has used the interaction between unsubstituted guanidinium cations and polysulfonate anions to prepare a wide range of open materials including cylindrical and lamellar architectures and networked cages. ${ }^{[11 a-g]}$ These systems show high levels of predictability, even though only one of the components (the sulfonate anion) can be varied.

We recently reported that tetraamidinium cations and dicarboxylate anions could be combined to prepare an open diamondoid framework in water. ${ }^{[12][13]}$ By considering polyamidinium and di/polycarboxylate units as node-and-linker motifs, we hypothesized that this system may offer a route to design and synthesize a family of frameworks and thus overcome one of the major remaining challenges in HOF chemistry

In the current work, we demonstrate that it is possible to prepare a family of robust hydrogen-bonded network materials using the amidinium $\cdots$ carboxylate interaction. ${ }^{[14]}$ Importantly, we are able to vary the structure of both the amidinium or carboxylate tecton, and introduce additional functionality while still retaining predictive power in terms of the framework structure. Accordingly, this work represents a first step towards synthesizing hydrogen bonded materials of pre-determined structures, thus realizing their potential for application to challenges in materials chemistry.

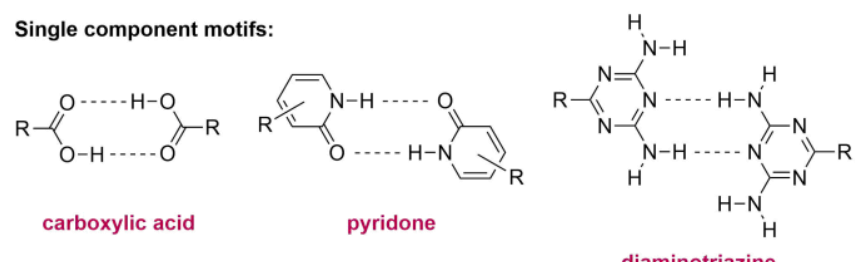

diaminotriazine

Two component motifs:
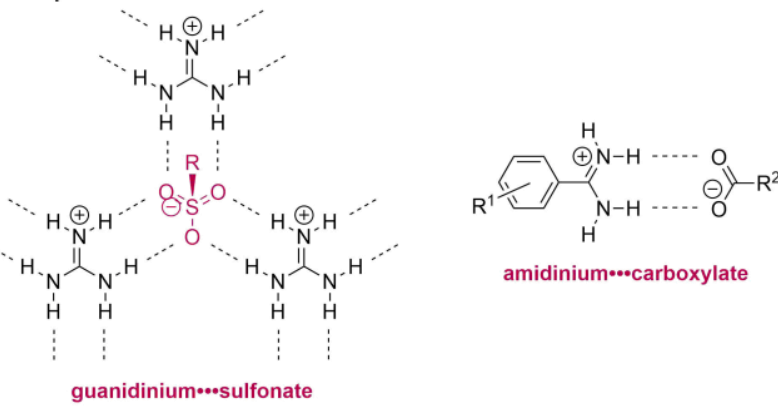

Figure 1. Key recognition motifs used in the preparation of hydrogen bonded framework materials. 


\section{Results and Discussion}

Framework series $\boldsymbol{A}$ (tetraamidinium ${1^{4+}}^{4}$ and dicarboxylates) We have previously reported the interpenetrated diamondoid framework $A^{\text {tere }}$ prepared by mixing amidinium $1.4 \mathrm{Cl}$ and $\mathrm{TBA}_{2}$.terephthlate in water. ${ }^{[12]}$ Building upon this result, we hypothesized that a similar structure could be prepared using the extended tecton $\mathrm{TBA}_{2}$-biphenyldicarboxylate. Indeed, mixing aqueous solutions of the two components resulted in rapid precipitation of a powder, but layering $\mathrm{EtOH} /$ water solutions of the two components gave crystals suitable for single crystal X-ray diffraction (SCXRD) studies.

As shown in Figure 3 , this compound is the framework $\mathbf{A}^{\text {biphen, }}$ which has a similar diamondoid structure to $\mathbf{A}^{\text {tere }}$, and the same $R_{2}^{2}(8)$ hydrogen bonding geometries. ${ }^{[15]}$ Unlike $\mathbf{A}^{\text {tere }}$, which crystallizes in a tetragonal space group and contains square channels with a diameter of $\sim 13 \AA$, $\mathbf{A}^{\text {biphen }}$ contains two different hexagonal channels, one with a diameter of $\sim 8.5 \AA$ and one with a diameter of $\sim 4 \AA$. The hexagonal packing of the diamondoid network appears to arise from small twists in both organic components. We were also able to prepare $\mathbf{A}^{\text {biphen }}$ by crystallization from DMSO/water, suggesting that the structures of these materials are less solvent-dependent than many HOFs. ${ }^{[16]}$

Having demonstrated that the structure of $\mathbf{A}^{\text {tere }}$ can be expanded by the use of a larger dicarboxylate, we next investigated whether functionalized linkers could be incorporated into the hydrogen-bonded network. Crystallization of $\mathbf{1 . 4 C l}$ and $\mathrm{TBA}_{2}$-aminoterephthlate or $\mathrm{TBA}_{2}$-anthracenedicarboxylate gave the frameworks $A^{\mathrm{NH} 2}$ and $A^{\text {anth }}$ (Figure 3). While these frameworks have the same diamondoid structure as $\mathbf{A}^{\text {tere }}$ and $\mathbf{A}^{\text {biphen, }}$ distortions are observed: in the structure of $\mathbf{A}^{\mathrm{NH} 2}$, half of the hydrogen bonding interactions are "offset" such that only one amidinium $\mathrm{N}-\mathrm{H}$ group and one carboxylate $\mathrm{O}$ atom engage in a significant hydrogen bond, ${ }^{[17]}$ while the other half have the expected $R_{2}^{2}(8)$ geometry. In the structure of $A^{\text {anth }}$, there is a bend associated with the amidinium $\cdots$ carboxylate interaction, which introduces a kink into the hydrogen-bonded network, and causes a significant flattening of the diamondoid structure. Nevertheless, functionalized organic links can be introduced into the framework with retention of the overall supramolecular structure.

To understand the generalizability of our synthetic approach, we next crystallized the bis(amidinium) $\quad \mathbf{2 \cdot 2} \mathrm{Cl}$ with the tetrahedral tetracarboxylate TBA $_{4} \cdot 4$, which gave the "reverse"
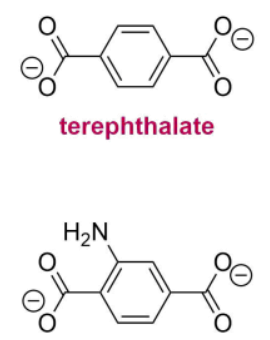

aminoterephthalate framework $\mathbf{A}^{\text {reverse }}$ (i.e. the reverse of $\mathbf{A}^{\text {tere }}$ ). This structure is very similar to the parent framework $\mathbf{A}^{\text {tere }}$, although crystallizes in an orthorhombic rather than tetragonal space group. While in this case, the preparation of the reverse framework is trivial, for future more complex materials the ability to be able to choose which tecton is the amidinium or carboxylate may offer considerable synthetic advantages.

Interestingly, $\mathbf{A}^{\text {biphen }}, \mathbf{A}^{\mathrm{NH} 2}, \mathbf{A}^{\text {anth }}$ and $\mathbf{A}^{\text {reverse }}$ remain crystalline on removal from solvent and subsequent drying (as indicated by PXRD studies, see Supporting Information). ${ }^{[18]}$ This is in contrast to $A^{\text {tere }}$, which lost crystallinity under these conditions. Two forms of $\mathbf{A}^{\text {tere }}$ were observed depending on the speed of crystallization: a kinetically-trapped open phase that formed within seconds and a thermodynamically-favoured phase that showed a higher degree of interpenetration and took hours to form. No such kinetic/thermodynamic isomerism is observed in any of the new diamondoid materials suggesting that they have more robust structures.

While the structure of the hydrogen-bonded networks are similar for all five frameworks, the crystal symmetry and packing changes substantially (Table 1 ). Calculated $\mathrm{N}_{2}$-accessible surface areas vary widely: $\mathbf{A}^{\mathrm{NH} 2}$ has no solvent-accessible pores, while $\mathbf{A}^{\text {biphen }}$ and $\mathbf{A}^{\text {anth }}$ have calculated surface areas in the range 500 $600 \mathrm{~m}^{2} \mathrm{~g}^{-1}$, and $\mathbf{A}^{\text {reverse }}$ has a surface area of $1100 \mathrm{~m}^{2} \mathrm{~g}^{-1}$. It is remarkable how apparently relatively minor differences in hydrogen bonding geometry lead to very large changes in both the degree of interpenetration and porosity of these closelyrelated materials.

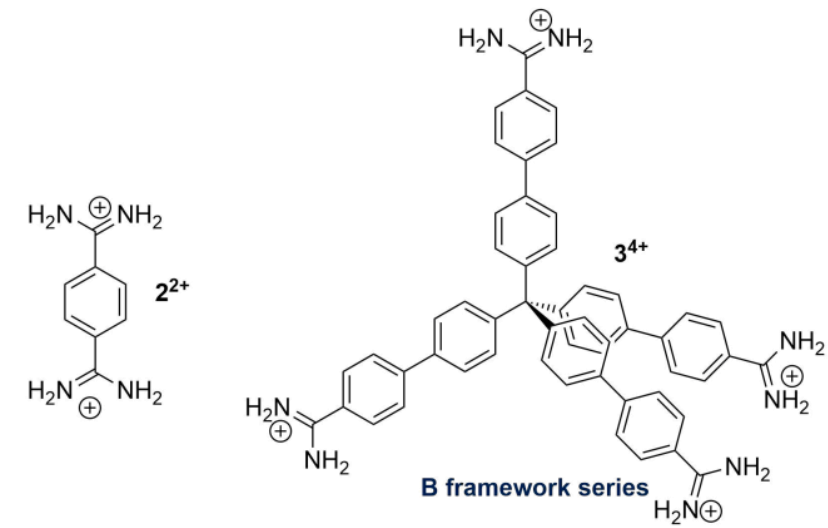

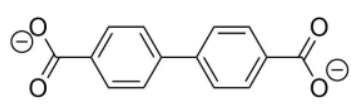

biphenyldicarboxylate

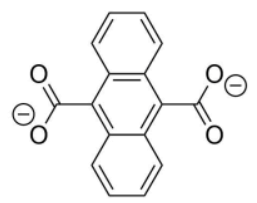

anthracenedicarboxylate

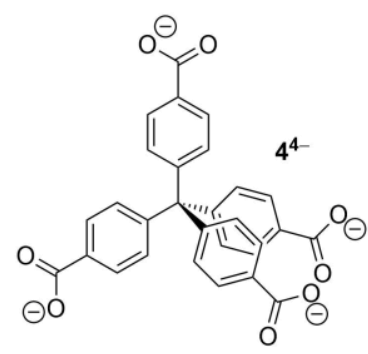

C framework series

Figure 2. Structure of amidinium and carboxylate tectons used in this study, and the key building blocks of the A, B and C frameworks prepared in this work. 

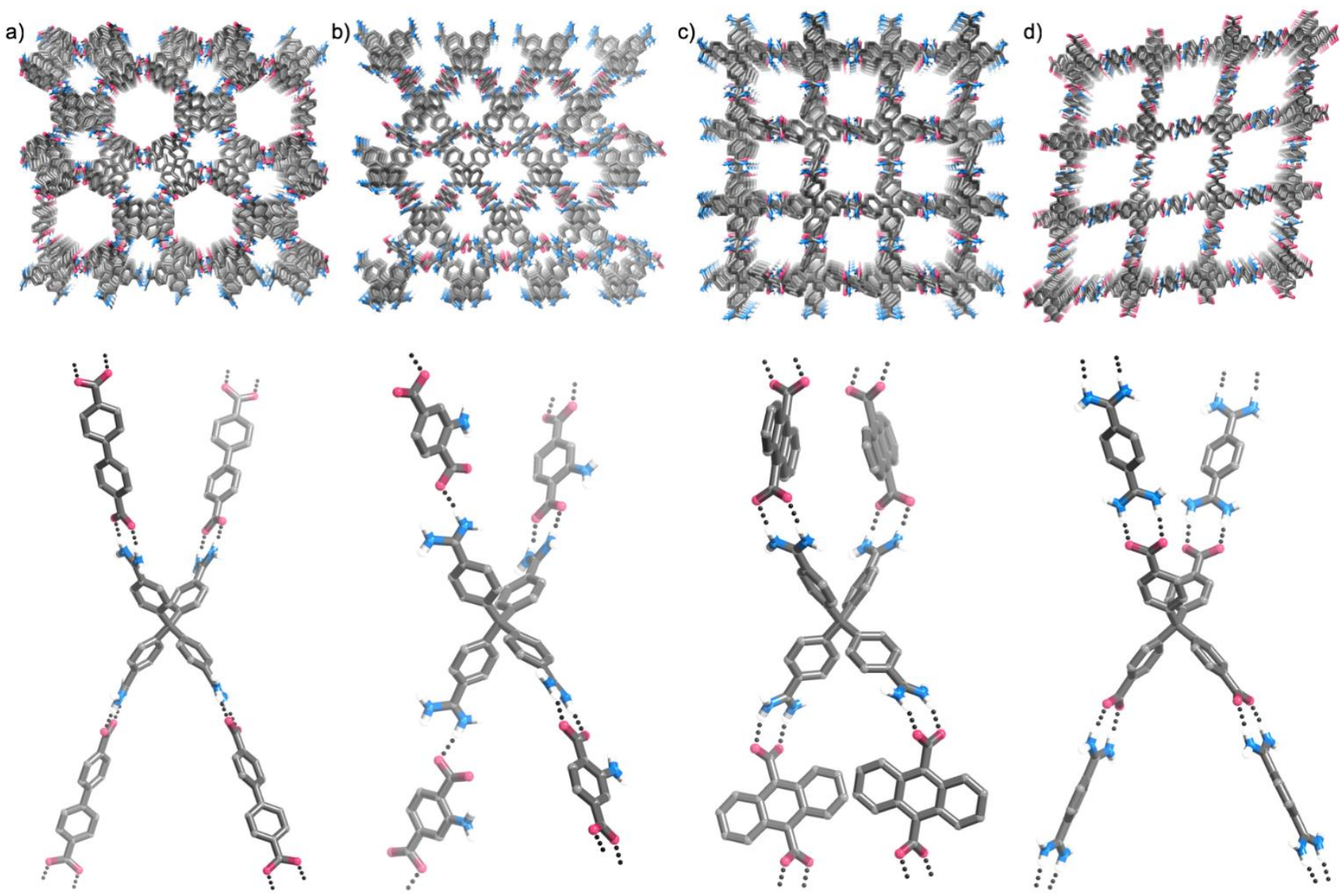

Figure 3 Structure and hydrogen bonding geometries in the X-ray crystal structures of a) $\mathbf{A}^{\text {biphen; }}$ b) $\mathbf{A}^{\mathrm{NH} 2}$; c) $\mathbf{A}^{\text {anth }}$ and d) $\mathbf{A}^{\text {reverse }}$. Solvent molecules and most hydrogen atoms omitted for clarity; in some cases, PLATON-SQUEEZE ${ }^{[19]}$ was used.

Table 1. Structural data for A family of frameworks.

\begin{tabular}{lcccc}
\hline Structure & $\begin{array}{c}\text { Crystal } \\
\text { system }\end{array}$ & $\begin{array}{c}\text { No. of } \\
\text { interpenetrating } \\
\text { networks }\end{array}$ & $\begin{array}{c}\text { Solvent } \\
\% \text { [a] }\end{array}$ & $\begin{array}{c}\text { Calculated } \\
\text { surface } \\
\text { area } \\
\left(\mathrm{m}^{2} \mathrm{~g}^{-1}\right)^{[\mathrm{b}]}\end{array}$ \\
\hline $\mathbf{A}^{\text {tere [c] [12] }}$ & tetragonal & 11 & 46 & 1590 \\
A $^{\text {biphen }}$ & hexagonal & 15 & 25 & 520 \\
A $^{\text {NH2 }}$ & monoclinic & 13 & 19 & 0 \\
A $^{\text {anth }}$ & tetragonal & 5 & 28 & 590 \\
A $^{\text {reverse }}$ & orthorhombic & 10 & 38 & 1100 \\
\hline
\end{tabular}

[a] Calculated using PLATON-SQUEEZE. ${ }^{[19]}[\mathrm{b}]$ Solvent accessible surface area calculated using $\mathrm{ZeO++}{ }^{[20]}$ with a probe radius of $1.82 \AA$. [c] This refers to the rapidly-formed isomer of $\mathbf{A}^{\text {tere }}{ }^{[12]}$

Framework series B (tetraamidinium $3^{4+}$ and dicarboxylates) Having demonstrated that a series of isostructural frameworks can be prepared from $\mathbf{1}^{4+}$, we next investigated whether we could expand the central core of the material to include the new tetra(biphenyl)methane-derived building block $3^{4+}$. Crystallization of $3^{4+}$ with terephthalate, biphenyldicarboxylate, aminoterephthalate and anthracenedicarboxylate gave a series of hydrogen-bonded frameworks, B.

Interestingly, while $\mathbf{B}^{\text {anth }}$ and $\mathbf{B}^{\text {biphen }}$ have diamondoid structures, $\mathbf{B}^{\text {tere }}$ forms open $2 \mathrm{D}$ structures containing large square channels. In this case, it appears that the flexibility of the biphenyl groups present in $3^{4+}$ allow this molecule to act as a pseudosquare planar, rather than tetrahedral, tecton. ${ }^{[21]}$ In contrast to $\mathbf{B}^{\text {tere }}, \mathbf{B}^{\text {biphen }}$ and $\mathbf{B}^{\text {anth }}$, which all contain the "paired" $R_{2}^{2}(8)$ hydrogen bonding geometry, $\mathbf{B}^{\mathrm{NH} 2}$ has a different hydrogen bonding arrangement in which half of the aminoterephthalate anions bind side-on. As a result, this structure does not contain significant channels (see SI for more details).

As was the case with the A family of structures, the B structures are generally significantly porous and highly interpenetrated (Table 2). Indeed $\mathbf{B}^{\text {biphen }}$ has 32 interpenetrated nets, which we believe to be the most interpenetrated hydrogen bonded framework yet reported. Despite this very high level of interpenetration, it possesses a modest surface area as a result of square channels running through the material. 

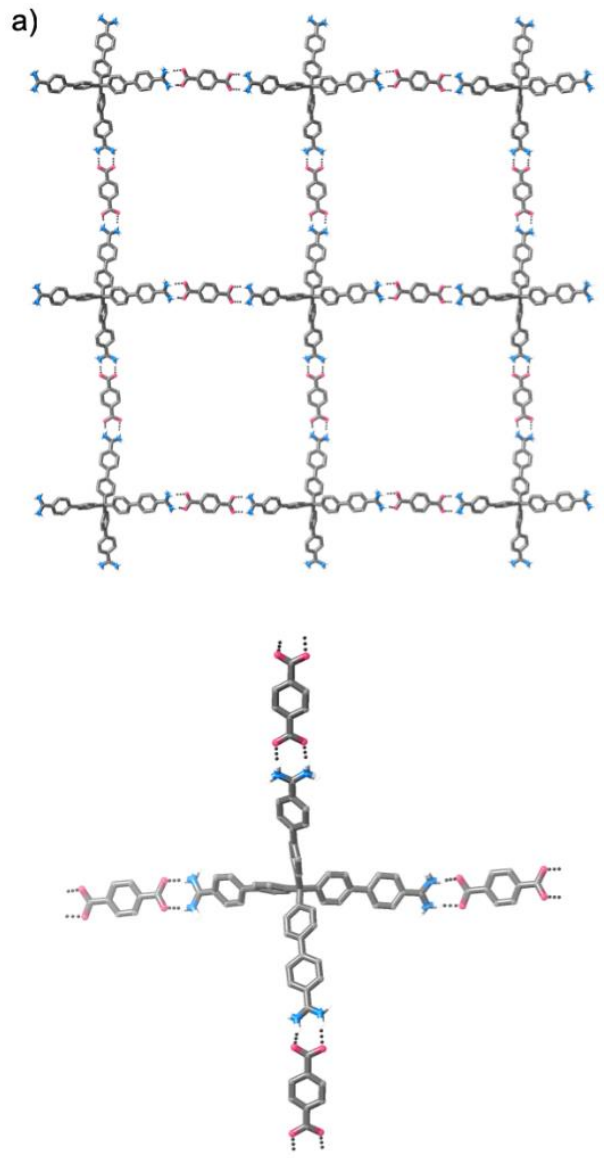

b)
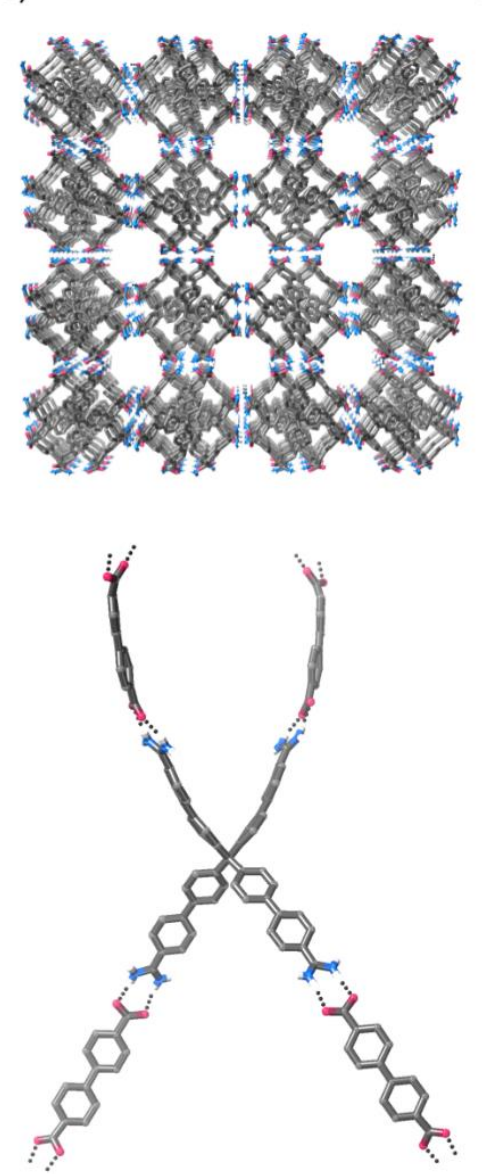

c)
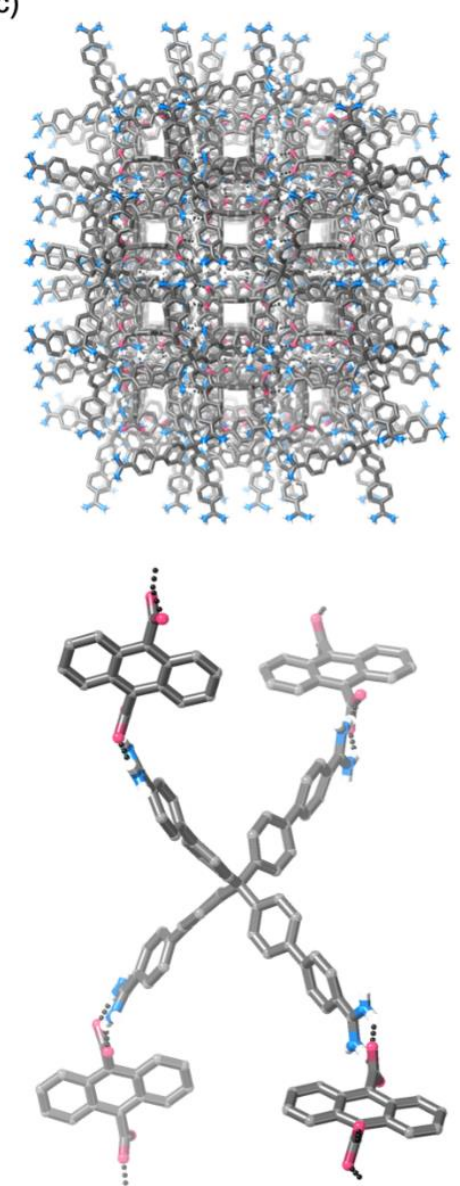

Figure 4 Structure and hydrogen bonding geometries in the X-ray crystal structures of a) $\mathbf{B}^{\text {tere; }}$ b) $\mathbf{B}^{\text {biphen; }}$ and c) Banth. Solvent molecules and most hydrogen atoms omitted for clarity; PLATON-SQUEEZE ${ }^{[19]}$ was used.

Table 2. Structural data for B family of frameworks.

\begin{tabular}{lcccc}
\hline Structure & $\begin{array}{c}\text { Crystal } \\
\text { system }\end{array}$ & $\begin{array}{c}\text { No. of } \\
\text { interpenetrating } \\
\text { networks }\end{array}$ & $\begin{array}{c}\text { Solvent } \\
\% \text { [a] }\end{array}$ & $\begin{array}{c}\text { Calculated } \\
\text { surface } \\
\text { area } \\
\left(\mathrm{m}^{2} \mathrm{~g}^{-1}\right)^{[\mathrm{b}]}\end{array}$ \\
\hline B $^{\text {tere }}$ & monoclinic & $6(2 \mathrm{D})$ & 35 & 1040 \\
B $^{\text {biphen }}$ & tetragonal & 32 & 17 & 390 \\
B $^{\text {anth }}$ & tetragonal & 18 & 33 & 0 \\
\hline
\end{tabular}

[a] Calculated using PLATON-SQUEEZE. ${ }^{[19]}$ [b] Solvent accessible surface area calculated using $Z e 0++{ }^{[20]}$ with a probe radius of $1.82 \AA$.

Framework series $C$ (tetraamidinium and tetracarboxylates) While the $\mathbf{A}$ and $\mathbf{B}$ series of frameworks both show good stability, we were interested to see whether materials could be prepared from two tetravalent tectons, as these may be even more robust. Crystallization of the tetra(phenylamidinium) $\mathbf{1}^{4+}$ and tetra(biphenylamidinium) $3^{4+}$ with the tetracarboxylate $4^{4-}$, again by simply mixing solutions of the components, gave the new frameworks $\mathbf{C}^{\text {phenyl }}$ and $\mathbf{c}^{\text {biphenyl }}$. Both have the expected diamondoid topology (Figure 5), and contain square channels. In both frameworks, these channels have a diameter of $\sim 9 \AA$. As was the case for the $\mathbf{A}$ and $\mathbf{B}$ series of frameworks, the structures are significantly interpenetrated but still contain significant solvent-accessible voids $\left(640\right.$ and $1130 \mathrm{~m}^{2} \mathrm{~g}^{-1}$ for $\mathbf{C}^{\text {phenyl }}$ and $\mathbf{C}^{\text {biphenyl }}$ respectively, Table 3$)$.

Table 3. Structural data for $\mathbf{C}$ family of frameworks.

\begin{tabular}{lcccc}
\hline Structure & $\begin{array}{c}\text { Crystal } \\
\text { system }\end{array}$ & $\begin{array}{c}\text { No. of } \\
\text { interpenetrating } \\
\text { networks }\end{array}$ & $\begin{array}{c}\text { Solvent } \\
\% \text { [a] }\end{array}$ & $\begin{array}{c}\text { Calculated } \\
\text { surface } \\
\text { area } \\
\left(\mathrm{m}^{2} \mathrm{~g}^{-1}\right)^{[\mathrm{b}]}\end{array}$ \\
\hline C $^{\text {phenyl }}$ & tetragonal & 6 & 29 & 640 \\
C $^{\text {biphenyl }}$ & tetragonal & 8 & 35 & 1130 \\
\hline
\end{tabular}

[a] Calculated using PLATON-SQUEEZE. ${ }^{[19]}$ [b] Solvent accessible surface area calculated using $\mathrm{ZeO++}{ }^{[20]}$ with a probe radius of $1.82 \AA$. 

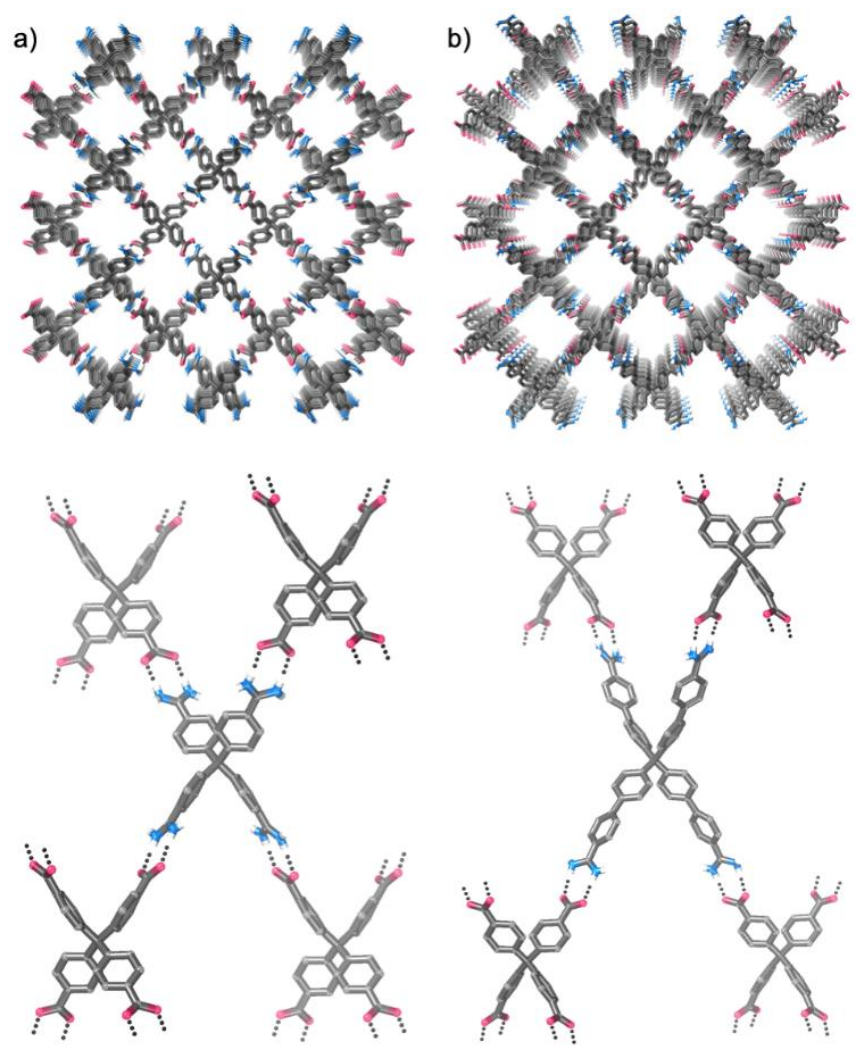

Figure 5 Structure and hydrogen bonding geometries in the X-ray crystal structures of a) $\mathbf{C}^{\text {phenyl }}$ and b) $\mathbf{C}^{\text {biphenyl }}$. Solvent molecules and most hydrogen atoms omitted for clarity; PLATON-SQUEEZE ${ }^{[19]}$ was used in the refinement of the structure of $\mathbf{C}^{\text {biphenyl. }}$

As an initial investigation into the stability of these materials, we tested the stability of $\mathbf{C}^{\text {phenyl }}$ by heating samples of the framework to $100{ }^{\circ} \mathrm{C}$ in either water or DMSO. Remarkably, the PXRD trace of the framework is completely unchanged after heating in water for 24 hours, and essentially unchanged after heating in DMSO for 1 hour ${ }^{[22]}$ (Figure 6). While several HOFs are known to exhibit stability in water, these materials are typically made from very hydrophobic components that have no aqueous solubility. In our case, both building blocks are highly soluble in water and it is remarkable that the hydrogen bonds holding the material together can survive prolonged heating in this solvent. It is also surprising that this material retains crystallinity when heated in DMSO, and indeed we believe this is one of very few hydrogen bonded materials to do so. ${ }^{[3 \mathrm{~d}]}$

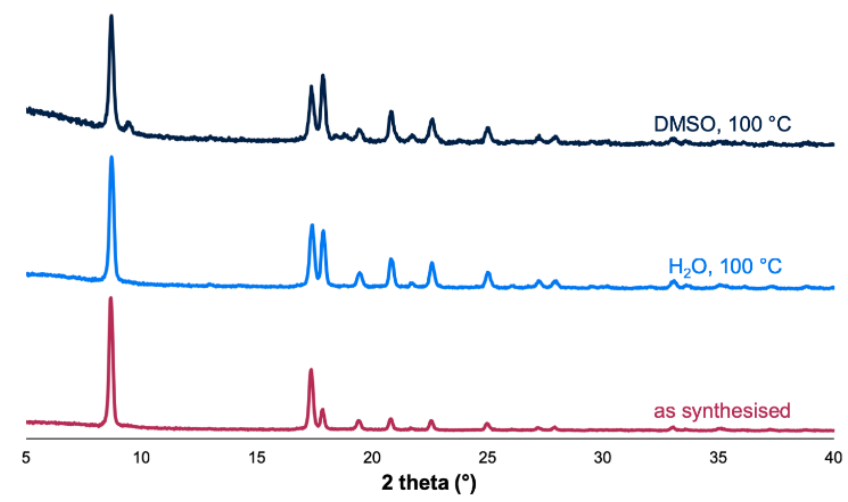

Figure 6 PXRD traces of $\mathrm{C}^{\text {phenyl }}$ as synthesized and after heating at $100{ }^{\circ} \mathrm{C}$ in water (24 hrs) or DMSO (1 hr).

\section{Discussion}

We have demonstrated the utility of the amidinium $\cdots$ carboxylate motif for the formation of a wide range of porous diamondoid frameworks. This approach is general and reproducible, but does have some limits; these are discussed briefly here, with more details provided in the Supporting Information. ${ }^{[23]}$

As previously discussed $\mathrm{B}^{\mathrm{NH} 2}$, forms a close-packed network that does not have the desired $\mathrm{R}_{2}^{2}(8)$ hydrogen bonding geometry. We also investigated the use of oxalate to prepare frameworks from the larger tetraamidinium tecton $3^{4+}$ and found that these did not give diamondoid materials, due to the ability of oxalate to bind either "front-on" or "side-on" to the amidinium group ${ }^{[24]}\left[i . e . R_{2}^{2}(8)\right.$ or $R_{2}^{2}$ (9) geometries]. ${ }^{[15]}$ Similarly, the use of flexible dicarboxylates based on amino acids did not give diamondoid networks - it would appear that the use of rigid building blocks with well-defined coordination vectors is necessary for predictable framework formation.

Flexibility may explain the observed $2 \mathrm{D}$ rather than $3 \mathrm{D}$ network topologies for the structures of $\mathbf{B}^{\text {tere }}$ - as the tectons get larger, they inherently become more flexible. While this structure still contains large open channels, it is no longer diamondoid. However, this is clearly not the only factor at play as the structure of $\mathbf{B}^{\text {biphen }}$, which contains the same amidinium tecton but a longer dicarboxylate, is diamondoid (although under different conditions, a few single crystals of a $2 \mathrm{D}$ form of $\mathbf{B}^{\text {biphen }}$ were isolated, see Supporting Information).

Generally the larger tecton, $3^{4+}$, present in the B family of frameworks, seems to give less predictable strucutres than the smaller tetraamidinium $\mathbf{1}^{4+}$. While $\mathbf{B}^{\text {biphen }}$ and $\mathbf{B}^{\text {anth }}$ form diamondoid networks, $\mathbf{B}^{\text {tere }}$ forms an open $R_{2}^{2}(8)$-bonded but nondiamondoid material, while $\mathbf{B}^{\mathrm{NH} 2}$ forms a close-packed structure that does not contain the desired $R_{2}^{2}(8)$ hydrogen bonding interactions. It may be possible to achieve diamondoid materials from these tectons by varying crystallization conditions (e.g. temperature or solvent) but this is clearly not quite as easy as for the A family of frameworks, where all five materials have crystalline diamondoid networks. Similarly, the A frameworks all crystallize (both as single crystals suitable for SCXRD studies and 
as bulk crystalline products) from $1: 1 \mathrm{EtOH}: \mathrm{H}_{2} \mathrm{O}$, while it was necessary to optimize crystallization solvents to obtain crystalline frameworks for the $\mathbf{B}$ materials. Using a $4^{-}$anion in the $\mathbf{C}$ frameworks seems to overcome these difficulties, as $\mathbf{C}^{\text {biphenyl }}$ crystallized readily from 1:1 EtOH: $\mathrm{H}_{2} \mathrm{O}$. Remarkably, in the case of $\mathbf{C}^{\text {phenyl }}$, mixing the two tectons causes immediate precipitation, but PXRD studies showed that this rapidly-formed material is crystalline.

It is interesting that while the number of interpenetrating nets varies significantly between frameworks (from 5-32), ${ }^{[25]}$ the \% solvent falls within a relatively narrow window (generally $20-40 \%$ ), and that samples within this range remain crystalline on drying. A previous amidinium $\cdots$ carboxylate framework had only four interpenetrating nets and a solvent content of $75 \%$ but lost crystallinity immediately upon removal from solvent, ${ }^{[13 b]}$ so these results suggest a certain degree of interpenetration is necessary to retain a robust structure. A more detailed analysis is provided in the Supporting Information.

Clearly longer tectons such as the tetra(biphenylamidinium) $3^{4+}$ and the biphenyldicarboxylate anion would be expected to favour crystal structures with a higher number of interpenetrating nets. However, even where frameworks with the same node and linker lengths are used, different degrees of interpenetration are observed (e.g. $\mathbf{A}^{\mathrm{NH} 2}, \mathbf{A}^{\text {anth }}$ and $\mathbf{A}^{\text {reverse }}$ have components with the same length but 5-13 interpenetrating nets). As well as the different steric demands of the dicarboxylate anions in these frameworks, it is apparent that bending/twisting of the tectons or the hydrogen bonds between them also impacts interpenetration. The hydrogen bonds in $\mathbf{A}^{\text {anth }}$ are significantly bent (Figure $3 c$ ) and this causes a major flattening of the diamondoid structure, reducing the potential for interpenetration (see Figure S41 for an

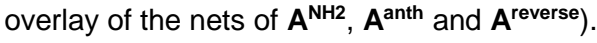

\section{Conclusions}

In this work, we have shown that the established node-and-linker concept well known in MOF chemistry can be extended to hydrogen bonded materials. A family of singly-crystalline frameworks was synthesized by simply combining amidinium and carboxylate tectons in water or water/alcohol mixtures. Importantly these materials can be prepared with a reasonable degree of predictability and both the cationic and anionic tectons can be modified. This has allowed us to incorporate additional functionality and tune the size of the hydrogen bonded nets. We have found that our approach does not appear to extend to flexible tectons, but generalizes well to building blocks with rigid geometries and well-defined coordination vectors. Preliminary investigations reveal that the materials are remarkably stable and can survive prolonged heating in water or DMSO.

\section{Experimental Section}

Amidinium compounds as their chloride salts were prepared from the corresponding nitriles in good yields using LiHMDS in THF followed by work-up with ethanolic $\mathrm{HCl}$. Carboxylates as their TBA salts were prepared from the corresponding carboxylic acids. Frameworks were prepared by simply mixing amidinium and carboxylate tectons in water/alcohol mixtures. In some cases, it was necessary to layer the solutions to slow down mixing in order to obtain crystalline products. All frameworks were prepared "in bulk" and characterized by PXRD, TGA, IR spectroscopy and ${ }^{1} \mathrm{H}$ NMR spectroscopy of the acid-digested material. Full details and characterization data are provided in the Supporting Information. CCDC 1902502-1902517 contain the supplementary crystallographic data for this paper. These data are provided free of charge by The Cambridge Crystallographic Data Centre.

\section{Acknowledgements}

NGW and CJD thank the Australian Research Council for funding. Part of this research was undertaken on the MX1 beamline ${ }^{[26]}$ at the Australian Synchrotron, part of ANSTO.

Keywords: crystal engineering $•$ hydrogen-bonded organic frameworks $•$ predictable synthesis $\bullet$ supramolecular chemistry • carboxylate anions

[1] O. Ermer, J. Am. Chem. Soc. 1988, 110, 3747-3754.

[2] a) M. Simard, D. Su, J. D. Wuest, J. Am. Chem. Soc. 1991, 113, 46964698; b) X. Wang, M. Simard, J. D. Wuest, J. Am. Chem. Soc. 1994, 116 12119-12120; c) J. D. Wuest, Chem. Commun. 2005, 5830-5837.

[3] a) Y.-F. Han, Y.-X. Yuan, H.-B. Wang, Molecules 2017, 22, 266; b) J. Luo, J.-W. Wang, J.-H. Zhang, S. Lai, D.-C. Zhong, CrystEngComm 2018 , 20, 5884-5898; c) N. G. White, Dalton Trans. 2019, DOI: 10.1039/c8dt0503a; d) R.-B. Lin, Y. He, P. Li, H. Wang, W. Zhou, B. Chen, Chem. Soc. Rev. 2019, 48, 1362-1389; e) I. Hisaki, C. Xin, K. Takahashi, T. Nakamura, Angew. Chem., Int. Ed. 2019, DOI: 10.1002/anie.201902147.

[4] a) W. Yang, A. Greenaway, X. Lin, R. Matsuda, A. J. Blake, C. Wilson, W. Lewis, P. Hubberstey, S. Kitagawa, N. R. Champness, M. Schröder, J. Am. Chem. Soc. 2010, 132, 14457-14469; b) Y. He, S. Xiang, B. Chen, J. Am. Chem. Soc. 2011, 133, 14570-14573; c) M. Mastalerz, I. M. Oppel, Angew. Chem., Int. Ed. 2012, 51, 5252-5255; d) X.-Z. Luo, X.-J. Jia, J.H. Deng, J.-L. Zhong, H.-J. Liu, K.-J. Wang, D.-C. Zhong, J. Am. Chem Soc. 2013, 135, 11684-11687; e) I. Hisaki, S. Nakagawa, N. Tohnai, M. Miyata, Angew. Chem., Int. Ed. 2015, 54, 3008-3012; f) A. Pulido, L. Chen, T. Kaczorowski, D. Holden, M. A. Little, S. Y. Chong, B. J. Slater, D. P. McMahon, B. Bonillo, C. J. Stackhouse, A. Stephenson, C. M. Kane, R. Clowes, T. Hasell, A. I. Cooper, G. M. Day, Nature 2017, 543, 657$664 ;$ g) F. Hu, C. Liu, M. Wu, J. Pang, F. Jiang, D. Yuan, M. Hong, Angew. Chem., Int. Ed. 2017, 56, 2101-2104; h) M. I. Hashim, H. T. M. Le, T.-H. Chen, Y.-S. Chen, O. Daugulis, C.-W. Hsu, A. J. Jacobson, W. Kaveevivitchai, X. Liang, T. Makarenko, O. Š. Miljanić, I. Popovs, H. V. Tran, X. Wang, C.-H. Wu, J. I. Wu, J. Am. Chem. Soc. 2018, 140, 6014 6026; i) Z. Bao, D. Xie, G. Chang, H. Wu, L. Li, W. Zhou, H. Wang, Z. Zhang, H. Xing, Q. Yang, M. J. Zaworotko, Q. Ren, B. Chen, J. Am Chem. Soc. 2018, 140, 4596-4603; j) Q. Yin, P. Zhao, R.-J. Sa, G.-C. Chen, J. Lü, T.-F. Liu, R. Cao, Angew. Chem., Int. Ed. 2018, 57, 76917696; k) P. Li, P. Li, M. R. Ryder, Z. Liu, C. L. Stern, O. K. Farha, J. F. Stoddart, Angew. Chem., Int. Ed. 2019, 58, 1664-1669. 
[5] a) W. Yang, F. Yang, T.-L. Hu, S. C. King, H. Wang, H. Wu, W. Zhou, J.R. Li, H. D. Arman, B. Chen, Cryst. Growth Des. 2016, 16, 5831-5835 b) A. Karmakar, R. Illathvalappil, B. Anothumakkool, A. Sen, P. Samanta, A. V. Desai, S. Kurungot, S. K. Ghosh, Angew. Chem., Int. Ed. 2016, 55 10667-10671; c) G. Xing, T. Yan, S. Das, T. Ben, S. Quu, Angew. Chem. Int. Ed. 2018, 57, 5345-5349.

[6] a) Z. Sun, Y. Li, L. Chen, X. Jing, Z. Xie, Cryst. Growth Des. 2015, 15, 542-545; b) H. Wang, Z. Bao, H. Wu, R.-B. Lin, W. Zhou, T.-L. Hu, B. Li, J. C.-G. Zhao, B. Chen, Chem. Commun. 2017, 53, 11150-11153; c) I. Hisaki, Y. Suzuki, E. Gomez, Q. Ji, N. Tohnai, T. Nakamura, A. Douhal, J. Am. Chem. Soc. 2019, 141, 2111-2121.

[7] a) B. F. Hoskins, R. Robson, J. Am. Chem. Soc. 1990, 112, 1546-1554 b) O. M. Yaghi, M. O'Keeffe, N. W. Ockwig, H. K. Chae, M. Eddaoudi, J. Kim, Nature 2003, 423, 705-714.

[8] a) A. P. Côté, A. I. Benin, N. W. Ockwig, M. O'Keeffe, A. J. Matzger, O. M. Yaghi, Science 2005, 310, 1166-1170; b) S. Kandambeth, K. Dey, R. Banerjee, J. Am. Chem. Soc. 2019, 141, 1807-1822.

[9] C. S. Diercks, M. J. Kalmutzki, N. J. Diercks, O. M. Yaghi, ACS Cent. Sci. 2018, 4, 1457-1464.

[10] a) M. Yoon, K. Suh, H. Kim, Y. Kim, N. Selvapalam, K. Kim, Angew. Chem., Int. Ed. 2011, 50, 7870-7873; b) H. Wahl, D. A. Haynes, T. le Roex, Chem. Commun. 2012, 48, 1775-1777; c) A. Yamamoto, S Uehara, T. Hamada, M. Miyata, I. Hisaki, N. Tohnai, Cryst. Growth Des. 2012, 12, 4600-4606; d) N. Roques, G. Mouchaham, C. Duhayon, S. Brandès, A. Tachon, G. Weber, J. P. Bellat, J.-P. Sutter, Chem. Eur. J 2014, 20, 11690-11694; e) T. Miyano, N. Okada, R. Nishida, A Yamamoto, I. Hisaki, N. Tohnai, Chem. Eur. J. 2016, 22, 15430-15436.

[11] a) V. A. Russell, M. C. Etter, M. D. Ward, J. Am. Chem. Soc. 1994, 116 1941-1952; b) V. A. Russell, C. C. Evans, W. Li, M. D. Ward, Science 1997, 276, 575-579; c) M. J. Horner, K. T. Holman, M. D. Ward, J. Am Chem. Soc. 2007, 129, 14640-14660; d) Y. Liu, C. Hu, A. Comotti, M. D. Ward, Science 2011, 333, 436-440; e) T. Adachi, M. D. Ward, Acc. Chem Res. 2016, 49, 2669-2679; f) M. Handke, T. Adachi, C. Hu, M. D. Ward, Angew. Chem., Int. Ed. 2017, 56, 14003-14006; g) Y. Li, M. Handke, Y.S. Chen, A. G. Shtukenberg, C. T. Hu, M. D. Ward, J. Am. Chem. Soc 2018, 140, 12915-12921; h) R. Custelcean, N. J. Williams, C. A. Seipp, Angew. Chem., Int. Ed. 2015, 54, 10525-10529; i) C. A. Seipp, N. J. Williams, M. K. Kidder, R. Custelcean, Angew. Chem., Int. Ed. 2017, 56 1042-1045; j) N. J. Williams, C. A. Seipp, F. M. Brethomé, Y.-Z. Ma, A. S. Ivanov, V. S. Bryantsev, M. K. Kidder, H. J. Martin, E. Holguin, K. A. Garrabrant, R. Custelcean, Chem, 2019, 5, 719-730.

[12] M. Morshedi, M. Thomas, A. Tarzia, C. J. Doonan, N. G. White, Chem Sci. 2017, 8, 3019--3025

[13] Since this report, a few other frameworks based on amidinium cations have been prepared, but a predictable family of related frameworks has not been realized: (a) M. Morshedi, N. G. White, CrystEngComm, 2017 19, 2367-2371; (b) M. Morshedi, J. S. Ward, P. E. Kruger, N. G. White Dalton Trans. 2018, 47, 783-790; (c) G. Xing, I. Bassanetti, T. Ben, S. Bracco, P. Sozzani, L. Marchio, A. Comotti, Cryst. Growth Des. 2018, 18, 2082-2092; (d) G. Xing, I. Bassanetti, S. Bracco, M. Negroni, C. Bezuidenhout, T. Ben, P. Sozzani, A. Comotti, Chem. Sci. 2019, 10, 730 736.

[14] a) F. Corbellini, L. Di Costanzo, M. Crego-Calama, S. Geremia, D. N. Reinhoudt, J. Am. Chem. Soc. 2003, 125, 9946-9947; b) Y. Tanaka, H. Katagiri, Y. Furusho, E. Yashima, Angew. Chem., Int. Ed. 2005, 44 3867-3870; c) H. Katagiri, Y. Tanaka, Y. Furusho, E. Yashima, Angew. Chem., Int. Ed. 2007, 46, 2435-2439; d) Y. Nakatani, Y. Furusho, E. Yashima, Angew. Chem., Int. Ed. 2010, 49, 5463-5467.

[15] J. Bernstein, R. E. Davis, L. Shimoni, N.-L. Chang, Angew. Chem., Int. Ed. 1995, 34, 1555-1573.

[16] Two crystal forms were identified by SCXRD studies: a diamondoid form identical to that prepared from $\mathrm{EtOH} / \mathrm{H}_{2} \mathrm{O}$ and a different structure. PXRD experiments suggest that the bulk material has the diamondoid structure (see Supporting Information).

[17] The $\mathrm{H} \cdots \mathrm{O}$ distance for this interaction is $2.07 \AA$, while that for the "noninteracting" oxygen atom is $2.59 \AA$.

[18] We are currently investigating ways to activate the frameworks reported in this paper so that we can study their gas absorption properties.

[19] A. L. Spek, Acta Crystallogr. 2015, C71, 9-18.

[20] T. F. Willems, C. H. Rycroft, M. Kazi, J. C. Meza, M. Haranczyk, Microporous Mesoporous Mater. 2012, 149, 134-141.

[21] We were also able to isolate a few crystals of $\mathbf{B}^{\text {biphen }}$ which had a very similar 2D structure. When prepared "in bulk," $\mathbf{B}^{\text {biphen }}$ is phase pure and has a diamondoid structure (as indicated by PXRD, see Supporting Information).

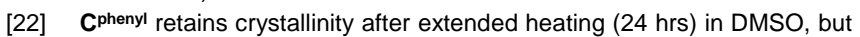
there appears to be a phase change beginning to occur, see Figure S122.

[23] A description of all crystallizations and their outcomes is provided on $p$. 38 of the Supporting Information.

[24] We previously observed unpredictable behavior when we reacted $1^{4+}$ with oxalate, in that case leading to a close-packed material containing one oxalate and two chloride anions per molecule of $1^{4+}$, see Ref. $13 \mathrm{a}$.

[25] Interestingly, the different degrees of interpenetration do not appear to be simply due to different solvents used in framework preparation. All the A and $\mathbf{C}$ frameworks were prepared in the same solvent $\left(1: 1 \mathrm{EtOH}: \mathrm{H}_{2} \mathrm{O}\right)$, but feature very different degrees of interpenetration.

[26] N. P. Cowieson, D. Aragao, M. Clift, D. J. Ericsson, C. H. Gee, Stephen J., N. Mudie, S. Panjikar, J. R. Price, A. Riboldi-Tunnicliffe, R. Williamson, T. Caradoc-Davies, J. Synchrotron Radiat. 2015, 22, 187-190 
